Title page

\title{
Reducing Inequality in Avoidable Emergency Admissions: Case Studies of Local Health Care Systems in England using a realist approach
}

Authors:

John Ford, Cambridgeshire and Peterborough Clinical Commissioning Group, Cambridge, UK jf653@medschl.cam.ac.uk

Julia Knight, Leicestershire County Council, Leicester, UK Julia.Knight@phe.gov.uk John Brittain, NHS England and NHS Improvement, UK john.brittain1@nhs.net Chris Bentley, Independent Public Health Consultant, UK chris.bentley19@gmail.com

Sarah Sowden, Population Health Sciences Institute, University of Newcastle, UK sarah.sowden@ncl.ac.uk

Ana Castro, Health Sciences, University of York, UK ana.castro@york.ac.uk

Tim Doran, Health Sciences, University of York, UK tim.doran@york.ac.uk

Richard Cookson, Centre for Health Economics, University of York, UK

richard.cookson@york.ac.uk

\section{Corresponding author}

John Ford

Cambridgeshire and Peterborough Clinical Commissioning Group

Lockton House

Clarendon Road

Cambridge

CB2 8FH

07966850109

jf653@medschl.cam.ac.uk

Conflicts of interest: None

Funding: JK's time was funded by the University of York (ESRC Impact Acceleration Account Award and Centre for Future Health Knowledge Impact and Translation Award) and the Wellcome Trust (Grant No. 205427/Z/16/Z) as a knowledge exchange partnership between NHS England and the University of York.

Author contribution: The study was conducted by John Ford (Peterborough and Cambridgeshire CCG) and Julia Knight (Leicestershire County Council) under the supervision of Richard Cookson (University of York) and John Brittain (NHS England), with advisory support from Chris Bentley (Independent Population Health Consultant), Tim Doran (University of York) and Sarah Sowden (University of Newcastle) and data analytical support from Ana Castro (University of York). 
Disclaimer: The views expressed in this publication are those of the authors and not necessarily those of the NHS, the Department of Health, the ESRC, the Wellcome Trust or the University of York. 


\section{Reducing Inequality in Avoidable Emergency Admissions: Case Studies of Local Health Care Systems Using a Realist Approach}

\section{Background}

People in disadvantaged areas are more likely to have an avoidable emergency hospital admission. Socio-economic inequality in avoidable emergency hospital admissions is monitored in England. Our aim was to inform local healthcare purchasing and planning by identifying recent healthcare system changes (or other factors), as reported by local health system leaders, that might explain narrowing or widening trends.

\section{Methods}

Case studies were undertaken in one pilot and five geographically distinct local health care systems (Clinical Commissioning Groups, CCGs), identified as having consistently increasing or decreasing inequality. Local settings were explored through discussions with CCG officials and stakeholders to identify potential local determinants. Data were analysed using a realist evaluation approach to generate context-mechanism-outcome (CMO) configurations.

\section{Findings}

Of the five CCGs two had narrowing inequality, two widening, and one narrowing inequality which widened during the project. We held 40 discussions with 45 CCG representatives including clinical staff, analysts, programme managers, patient representatives and public health specialists.

None of the CCGs had designed a large-scale package of service changes with the explicit aim of reducing socio-economic inequality in avoidable emergency admissions and local decision makers were unfamiliar with their own trends. Potential primary and community care determinants included: workforce; case finding and exclusion; proactive care coordination for patients with complex needs; and access and quality. Potential commissioning determinants included: data use and incentives; and targeting of services. Other potential determinants included changes in care home services, national A\&E targets, and wider issues such as public services financial constraints, residential gentrification, and health care expectations.

\section{Conclusion}

We did not find any bespoke initiatives that explained the inequality trends. The trends are more likely due to an interplay of multiple healthcare and wider system factors. Local decision makers need greater awareness, understanding and support to interpret, use and act upon inequality indicators. They are unlikely to find simple, cheap interventions to reduce inequalities in avoidable emergency admissions. Rather, long-term multifaceted interventions are required that embed inequality considerations into mainstream decision making.

\section{Keywords:}


Health inequalities, avoidable admissions, healthcare systems, quality improvement 


\section{Introduction}

People from socio-economically disadvantaged areas are more likely to have a potentially avoidable hospital admission. For example, people living in the most disadvantaged fifth of neighbourhoods in England have a 71\% higher emergency admission rate than those in the most affluent fifth with inequality in hospital admissions estimated to cost the NHS about $£ 4$.8billion per year ${ }^{1}$. Emergency admissions have been steady growing over the past 10 years, even after adjustment for an aging population the Health Foundation found that admissions grew by $1.1 \%$ per year ${ }^{2}$. About 1 in 7 emergency admissions are classified as "avoidable" (from a health service perspective) or "ambulatory care sensitive" because they reflect conditions, such as asthma and heart failure, for which good quality primary care could prevent acute deterioration demanding emergency admissions ${ }^{3}$. About three quarters of ambulatory care sensitive admissions are admitted through emergency departments and the commonest reasons are influenza and pneumonia, chronic obstructive pulmonary disease and ear, nose and throat infections ${ }^{4}$. The proportion of ambulatory care sensitive admissions to all admissions has increased over time from $4.4 \%$ in 2013 to $5.1 \%$ in $2018^{4}$.

Differences in these avoidable emergency admissions to hospitals are closely associated with socio-economic disadvantage; a previous study of over 3 million admissions in the UK estimated that over $70 \%$ of small area geographic variation in admission rates was associated with deprivation ${ }^{5}$ and most, but not all, of this was driven by deprivation-related differences in morbidity ${ }^{6}$. Other studies have found that primary care quality is significantly associated with avoidable emergency admissions, although the contribution is small ${ }^{7}$, and quality of primary care tends to be worse in deprived areas ${ }^{8}$. Prentice and colleagues found that hospitals with longer waiting times also had higher admissions for avoidable emergency 
admissions ${ }^{9}$, while this may be due to uncontrolled confounding, it may also be possible that delays in secondary care led to more avoidable emergency admissions. In the UK, deprivation is usually measured using the Index of Multiple deprivation which is a relative measure consisting of seven weighted domains; Income; Employment; Education; Skills and Training; Health and Disability; Crime; Barriers to Housing Services; Living Environment ${ }^{10}$.

In England, the NHS has a mandate to reduce health inequalities in access and outcomes through improved service design and delivery and "must ensure commissioning focuses on measurable reductions in inequalities in access to health services, in people's experience of the health system, and across a specified range of health outcomes"11. Commissioning mostly occurs through Clinical Commissioning Groups (CCGs), which receive about $75 \%$ of the NHS budget to commission and plan local health care services. There are currently 135 CCGs, covering an average population of 440,000 (range 100,000 to 2 million). Part of the inequalities mandate involves the publication of local indicators showing inequality in avoidable emergency admission ${ }^{12}$. One of these indicators is the Absolute Gradient Index (AGI) of deprivation-related inequality in emergency hospitalisation for chronic ambulatory care sensitive and urgent care sensitive conditions ${ }^{13}$. The AGI is a slope index of inequality (a weighted measure of the absolute difference in health indicators between the most and least disadvantaged population groups) which is comparable between different local populations because it uses national rather than local ranks of deprivation as the independent variable.

In December 2018, NHS England published local data packs for each CCG with in-depth analyses of local AGI indicator trends ${ }^{14}$, showing that inequality in avoidable emergency 
admissions narrowed over time in some CCGs and widened in others. In the absence of a detailed understanding of local context, however, the reasons for these divergent local trends and lessons for policy-makers remain unclear. We therefore aimed to identify recent healthcare system changes and other factors, as reported by local health care leaders, that might plausibly help to explain widening or narrowing inequality in avoidable emergency admissions them using realist methods ${ }^{15}$. We had the following objectives:

1. Identify example CCGs with narrowing or widening inequality in avoidable emergency admissions.

2. Identify potential explanations for these inequality trends and their underlying mechanisms, with particular attention to recent system-wide changes in local healthcare organisation and delivery.

Realist approaches are an established methodology that seeks to understand the context and underlying mechanisms that produce outcomesp $\mathrm{p}^{15}$. The methods allow research to explore the contexts in which interventions occur to understand how these contexts produce different outcome. An established analytical approach is used through generating context-mechanism-outcome (CMO) configuration which combine to produce one overall programme theory. Although our primary focus was on factors under the control of local health care planners, we also explored wider determinants of inequality trends in potentially avoidable emergency admissions. While the data packs primarily focus on socioeconomic inequality, we also asked our informants to consider other aspects of social disadvantage, such as ethnicity, which may contribute to socio-economic differences. 


\section{Methods}

Case studies adopting a realist approach were used. Five sites, with one pilot, were chosen to balance sufficient depth of analysis and breadth of experience. Formal ethical approval was not required because the project met the Health Research Authority definition of Service Evaluation ${ }^{16}$. This was confirmed by the chair of the University of York Department of Health Science Research Governance Committee.

Identification of case study CCGs

We used two different data sources to identify candidate CCGs with either widening or narrowing inequality. The first and primary source was the official NHS England AGI indicator data from the CCG Improvement and Assessment Framework; available at CCG level for a three-year period from $2015 / 16$ to $2017 / 18$. The second source was the University of York AGI data for upper tier local authorities; available for a five-year time period from $2012 / 13$ to $2016 / 17^{17}$. We initially identified CCGs with a consistently increasing or decreasing trend in AGI (defined as three annual time periods) in the NHS England data and local authorities with consistent increase or decrease (defined as the trend for three or more time-periods). We then cross-validated the local authorities to the associated CCG.

This process produced a longlist of potential CCGs which was reviewed by two team members (JF and JK) independently to produce a shortlist of potential case study sites based on the following criteria:

1) Consistent trends in the CCG and local authority data; 
2) Range of deprivation in the CCG, prioritising those CCGs with neighbourhoods across all national deprivation decile groups;

3) Consistent trend of AGI shown in the associated publicly available NHS packs

Case studies were then selected from the shortlist through discussion within the research team to identify geographically discrete CCGs with the steepest gradients.

We conducted a pilot case study to test and refine the methodology, including processes for organising discussions with CCG staff, collecting data and applying realist evaluation principles. The pilot site was selected for reasons of geographical convenience and where relevant data was included.

Case study methodology

The Clinical Chair or Accountable Officer of each of the chosen CCGs was approached (via a formal letter sent by email) to discuss the evaluation with the project leads (JF and JK). CCGs were informed about what the data showed and purpose of the evaluation. Once a CCG agreed to take part (all did), we undertook a desktop review of publicly available documents and data using national data sources, such as the PHE Fingertips tool ${ }^{18}$, local Joint Strategic Needs Assessment websites and documents on the CCG and associated LA website to understand the local area before speaking to staff. Information was gathered in a single, standardised format which informed subsequent visits.

A member of the CCG helped to arrange a series of discussions with key CCG officials and stakeholders; usually over two days. Where possible both evaluation leads attended. The 
key stakeholders requested included: Clinical Chair; Accountable or Chief Officer; Head of Programme Analytics or data analyst; commissioning lead for primary care; commissioning lead for urgent/emergency care; lay member of CCG; and Director of Public Health or Public Health consultant (as they hold CCG board positions). Discussions were either held with individuals or small groups depending on local arrangements and were guided by a list of standard questions (see Supplementary Material). The focus of discussions included actions that the CCG had undertaken to address health inequalities, as well as any significant system-wide changes over the past three to five years. Where explanations were suggested by staff, data or more detailed evidence to ascertain the credibility of statements was requested. Discussions were audio-recorded, but not transcribed because of capacity constraints. Field notes were taken during and after the meetings. Data was collected from March to October 2019.

The evaluation leads independently re-listened to all discussion audios to generate CMO configurations for each CCG using a realist logic of analysis ${ }^{15}$. These were then compared and discussed to agree a list of CMOs for each site. CMOs were further refined based on additional information provided from the CCG after the discussions alongside revisiting the discussion audios; with some CMOs being dropped or other given more weight depending on their credibility. For example, if a certain factor was mentioned but occurred after the change in inequalities trend this would viewed as less credible than factors which had a credible temporal relationship. The CMOs from each site were then synthesised into one overall list by grouping them together into broad categories. This was presented in a programme theory diagram. The $\mathrm{CMO}$ configurations describe the main potential determinants and underlying mechanisms raised by informants but are not intended to be 
mutually exclusive or independent. The initial findings were sent to the local participating health systems to ensure factual accuracy and discussed at a multi-disciplinary workshop. 


\section{Findings}

Based on the two data sources, we produced a longlist of 52 potential CCGs. Using the criteria, we then identified a shortlist of 16 potential sites, with three geographical clusters in London, Manchester and Essex, and selected five sites. Two had narrowing inequality (CCG A-Improving, CCG B-Improving) which we labelled "Improving", one had narrowing inequality which widened during the course of the evaluation, which we labelled "Improving then worsening" (CCG C-Mixed) and two had widening inequality (CCG D-Worsening and CCG E-Worsening) which we labelled "Worsening". CCG D-Worsening has a joint management structure with another CCG, so data was collected on both CCGs. The trend for each CCG is shown in the Supplementary Material.

In total we held 40 discussions across all CCGs with 45 different representatives (see table 1). The number of individuals spoken to within each CCG ranged from five to ten.

Overarching programme theory

Most of the health care officials we spoke to were aware of the data packs but could not describe the contents or broad implications for their CCG, with the exception of data analysts. None of the CCGs we visited reported specific services or strategies were in place currently or previously to reduce inequality in avoidable hospital admissions. Those CCGs with a reducing inequality in avoidable hospital admissions had consciously put plans in place with the specific aim of reducing inequalities in avoidable emergency admissions. However, all had services and plans in place to reduce the total level of avoidable emergency admissions. 
From discussions, we identified 17 factors that contributed to the inequality trend in avoidable emergency admissions, as shown in Figure 1 and Table 2 (and supplementary material). We identified five key drivers of change in avoidable emergency admissions inequality, four within the health system and one wider factor beyond the control of the health system.

1. Design and delivery of primary care and NHS community healthcare services

CCG staff considered that both changes in access to and quality of primary care were important for managing complex patient cases in the community setting. In CCG C-Mixed and $E$-Worsening staff reported that practices with worsening performance in recent years (exemplified by poorer Care Quality Commission ratings) tended to be in more disadvantaged areas and this may lead to higher avoidable emergency admissions (CMO1 in Table 3).

CCG C-Mixed reported having undertaken programmes of work in some of the most deprived areas to identify patients who consistently exception reported (excluded) from the quality outcome framework (QOF) system (quality-related programme of financial incentives in primary care) as they do not respond to invite letters and are considered difficult to engage with. Through efforts to identify and support these cohorts, they reported improved engagement in primary care $(\mathrm{CMO} 2)$. This meant patients were more likely to contact primary care earlier and during acute deterioration, rather than automatically attending A\&E. In CCG C-Mixed, this was coupled with a Focused Care programme established in 2010 that aspired, in conjunction with partners, to deliver 
proactive care in disadvantaged areas to improve prevention, health literacy, selfmanagement and community development (CMO3). The programme also provided proactive health and welfare support to individuals with health and wider social issues that put them at an increased risk of emergency attendance and admission (CMO4).

Reduced workforce capacity and capability in primary care in recent years was a recurrent theme. A reduction in both primary care and community care workforce over time, especially in disadvantaged areas, was reported to reduce the ability to deal with acute deterioration making emergency admissions more likely (CMO5). According to informants in CCG-D Worsening, the deterioration in primary care staff's capability to manage patients with complex health and social needs could be due to recent retirement of senior GPs who have had been leaders within the health care system who are replaced by either younger doctors or allied health professionals that are likely to be more risk adverse and refer patients directly to $A \& E$ (CMO6). To overcome workforce issues, some practices relied on short-term locums who are not necessarily able to provide the same level of continuity of care, and this might have led to a decreased likelihood of trying to manage acute deteriorations in the community (CMO7). If indeed reduced workforce capacity and capability in recent years was more prevalent in disadvantaged practices, this may explain the widening socio-economic inequalities in avoidable emergency admissions over time experienced in some CCGs.

Primary care staff in CCG-E Worsening reported that increased time pressures in recent years, coupled with increased communication challenges, led to increased uncertainty of 
diagnosis and a higher likelihood of urgent referral to secondary care or attendance at A\&E for investigations to rule out serious pathology (CMO8).

CCG B-Improving and C-Mixed reported the positive effect of merging general practices in underserved areas and using specific contracts (such as the Alternative Provider Medical Service contract targeted at underserved areas) to improve primary care access in more deprived areas (CMO9).

\section{Key performance indicators in secondary care settings}

Increasing difficulty in meeting the national four-hour wait target for A\&E care (95\% of patients to be seen within four hours of attendance) was reported to lead to an increased likelihood of short-stay emergency admission especially for people with complex health or social needs who were more likely to be disadvantaged (CMO10).

\section{Preventative interventions in community care settings}

In some areas, CCG staff reported that many care homes are situated in deprived areas and that interventions aimed at improving specific care home services and reducing avoidable emergency admissions may have led to reductions in emergency admissions from deprived areas (CMO11). One example was a care home support package introduced in care homes in CCG C-Mixed in 2014/15 to proactively plan healthcare for care home residents. GPs were allocated care homes in their patch and incentivised to deliver six monthly holistic reviews of residents and put in place anticipatory care plans. An audit, following the programme's 
introduction, is reported to have found that emergency admissions reduced (personal communication Clinical Director for Urgent Care, CCG C-Mixed).

4. Oversight and process of commissioning local health services

CCG B-Improving developed a local primary care dashboard that collated and provided general practices with their own metrics. This allowed GPs and primary care leads to benchmark practices in the CCG. CCG staff reported that this was effective in improving performance and reducing admissions in practices with high admissions because of peer pressure (CMO12). Furthermore, CCG B-Improving reported processes to identify and support practices that were struggling and introduction of financial incentives, through locally enhanced services in primary care that aimed to help minimise unnecessary emergency hospital admissions (CMO13). The CCG also tried to engage with member practices in health care service design and transformation. Approaches included monthly meetings between GPs and CCG leads, being on hand to support primary care practice and clear messages about practice specific targets.

The use of data, or lack, was reported to be important by CCG staff. Staff from two CCGs reported not having an "operating structure to use data", such as mapping admissions by small area. Additionally, restrictions introduced as part of the Health and Social Care Act 2012, were reported to have impeded access to patient level data. However, there were reports, such as from CCG B-Improving, of health service commissioners using datainformed approaches to target services to the highest need and inequality (CMO14).

5. Wider socio-economic, cultural and environmental changes in the local area 
In CCGs C-Mixed, E-Worsening and A-Improving staff reported that their local area had become either more gentrified or more deprived. CCG A-Improving has become increasingly gentrified, with some of the traditionally more deprived areas being redeveloped. This resulted in a change in the composition of the local populations. More affluent people moving to CCG A-Improving and more people on lower incomes moving into CCG C-Mixed and E-Worsening. In turn this changed the health needs of the population and requirement for secondary care. When this interacts with financial constraints within public services, there can be worsening community resilience leading to a reduction in the ability to manage health problems in the community (CMO15 and $\mathrm{CMO} 16)$.

CCG C-Mixed had been used as a pilot site for the roll-out of Universal Credit (a payment to help with living costs given to people on low incomes, out of work or who cannot work) and staff reported this had resulted in many residents facing significant financial hardships, especially in the most deprived areas of the CCG (CMO16). In turn this may have led to deteriorating mental and physical health with reduced resilience and capacity to remain independent in the community.

Most CCGs also mentioned the influence of increasing international migration on health inequalities. Individuals who moved to the UK were reportedly more likely to live in more deprived areas because of the cheaper living costs. In the context of a high proportion of people with different experience and expectations of health care, there is confusion and reduced healthcare services literacy, resulting in an increased likelihood of attendance at the local A\&E (CMO17). 



\section{Discussion}

\section{Summary of principal findings}

We did not find a simple explanation for any of the increasing or decreasing trends in our five CCG sites, and none of the CCGs had specifically designed a large-scale package of service changes with the explicit aim of reducing socio-economic inequality in avoidable emergency admissions. We did, however, identify several potential contributing factors. Primary and community care factors included: (i) workforce; (ii) case finding and exclusion; (iii) proactive care co-ordination for patients with complex needs; and (iv) access and quality. Commissioning process factors included; (i) data use and incentives; and (ii) targeting of services. Other potential determinants included changes in care home services, national A\&E targets, and wider non-care factors such as financial constraints on public services, residential gentrification and shifting health care expectations within the population.

\section{Strengths and limitations}

A key strength of our approach was the data-driven identification of case study sites through the triangulation of two data sources using tests of statistical significance and consistency of trends. Our design adds value to the existing literature by focusing on whether recent changes in system-wide health care factors led to recent changes in inequality. We were aware of the risk of spuriously identifying inequality trends in CCGs that merely experienced transient "data blips" due to random health events and/or measurement artefacts, and therefore several criteria were employed to determine robust and sustained inequality trends. Another strength was our use of an established realist case 
study methodology ${ }^{19}$ which enabled not only the identification of possible contributing factors, but also the underlying mechanisms.

There were, however, several limitations. First, we were not able to undertake quantitative causal inference analysis to examine the empirical validity of the hypothesised CMOs because of time constraints and access to suitable data. For example, staff reported positive impacts of the "missing thousands" initiative in the late 2000s, as part of the National Health Inequalities Support Team programme, which sought to reduce exception reporting (the process by which general practices can exclude patients who do not engage from quality-related financial incentives) and improve case finding. However, this was never formally evaluated. Second, time constraints also meant that we were not able to transcribe the interviews and relied on re-listening to the audio to undertake the analysis. Third, due to health service pressures, interviews with some providers were cancelled at short notice reducing the breadth of data gathered. Fourth, we relied on CCG staff to identify suitable informants and although this enabled us to access high-level individuals, some did not have much organisational memory of the local health system and CCG. Fifth, staff recall may have been affected by the reason for selection (improving or worsening inequality trend). Finally, the AGI trends reported in the data packs used 2015 deprivation scores and we therefore do not know the potential impact of changes in deprivation over time.

\section{Meaning of the findings}

Avoidable emergency admissions are a long-standing indicator, but data showing the inequality in avoidable emergency admissions is new and not yet embedded into health care 
systems. The AGI indicator has hitherto been a low-profile indicator, one of 58 quality improvement indicators within the CCG Improvement and Assessment Framework (IAF), and the associated data pack drawing attention to this indicator was only disseminated in December 2018. It is therefore not surprising that health systems were not familiar with the indicator or that it has not yet been used to drive improvements. COVID-19 has raised the priority of health inequalities for health care organisations, therefore inequalities indicators may gain greater prominence in driving improvements going forwards.

The seventeen factors that we identified show the complexity and interaction of multiple factors. It is unlikely that any single intervention or activity had led to the reduction, but the interaction of multiple healthcare and non-health care factors.

\section{Comparison with existing literature}

There has not yet been a systematic review specifically focusing on evidence about interventions to reduce inequalities in avoidable hospital admissions, though one is currently underway ${ }^{20}$. However, there have been systematic reviews of interventions to reduce average levels of avoidable hospital admissions, which have highlighted the importance of primary care access, quality and workforce ${ }^{3,21-25}$. Busby and colleagues undertook a review to explore factors that explain geographic variation in avoidable emergency admissions. Based on 39 studies, the authors found that variation could be due to primary care quality and this factor was highlighted in our evaluation. Gibson and colleagues (in a review of avoidable admissions for diabetes) found several contributing factors, including workforce and primary care access and quality ${ }^{23}$. However, Sheringham and colleagues found that primary care quality and workforce were not associated with 
inequality in avoidable emergency admissions ${ }^{26}$. The differences between Sheringham and colleague's study and ours may be because Sheringham and colleagues looked at the average effect across all areas of England, whereas the areas we explored may have had particular contextual challenges. Therefore, it may not be poor quality primary care by itself, but rather the interaction of poor quality with other factors such as barriers to access, workforce shortages, weak community assets and/or changing demographics which leads to the widening of inequalities. Our study did not identify other factors mentioned in previous literature reviews focused on average avoidable emergency admissions levels, such as Comprehensive Geriatric Assessment, vaccination or emergency care practitioners ${ }^{27-29}$. This may be because these are not as relevant to the local areas we evaluated or were not commissioned by the CCGs. It may also be because previous reviews have focused on interventions to address avoidable emergency admissions per se, rather than interventions to address inequalities in avoidable emergency admissions.

Implications for policy

There are no cheap and simple "magic bullet" interventions guaranteed to reduce inequality in avoidable emergency admissions. Instead sustained, large-scale interventions across the health system are likely to be required that are tailored to specific local population needs. Promising approaches include strengthening primary care in deprived areas by: (i) ensuring adequate workforce, quality, access and continuity; (ii) promoting engagement with primary care services through case finding and reducing exception reporting; and (iii) improving adherence to effective treatments for chronic diseases and community infrastructures. 
Proactive models of care for patients with complex health and social needs should be considered, such as the Focused Care programme of integrated primary care and welfare services ${ }^{30}$. Health systems should target resources, especially primary care services, to neighbourhoods with the greatest needs rather than universal offers being made to all neighbourhoods ${ }^{31}$. With the NHS facing increasingly limited resources, driven by higher use and costs of healthcare, there is a moral imperative to ensure that scare resources are distributed in an equitable fashion and for inequalities to be a high priority in every local health care system.

Implications for future research

Several of the factors we identified could be explored further in quantitative studies using administrative data linked at individual, neighbourhood or practice level, including both quasi-experimental intervention effectiveness studies and causal pathway modelling studies. For example, exploring the association between the AGI measure and access to general practice, workforce, quality of primary care, A\&E targets, universal credit and exception reporting. Since the determinants of change in emergency admission inequality are complex, it would be preferable to explore several different factors within the same analysis to allow for confounding, mediating and moderating influences and to compare the importance of different factors. Our findings could be extended by further case studies with more bespoke local data analyses, wide-ranging interviews and documentary analysis, new case studies in different areas, and a more systematic review of evidence on effective interventions for reducing inequality in emergency admissions. 


\section{Conclusions}

We could not find any single service or initiative that explained the trends in inequality in avoidable emergency admissions. Rather, the trends are more likely due to an interplay of multiple competing or compounding healthcare and wider system factors. The contributing factors we identified mainly focused on primary care and commissioning, and to a lesser extent care home services, national A\&E targets, and wider non-healthcare factors. Local decision makers need greater awareness, understanding and support to interpret and use inequality indicators. 


\section{References}

1. Asaria M, Doran T, Cookson R. The costs of inequality: whole-population modelling study of lifetime inpatient hospital costs in the English National Health Service by level of neighbourhood deprivation. J Epidemiol Community Heal 2016; 70: 990-996.

2. Tallack C, Charlesworth A, Kelly E, et al. The bigger picture. Epub ahead of print 15 October 2020. DOI: 10.37829/HF-2020-RC10.

3. Steventon A, Deeny S, Friebel R, et al. Briefing: Emergency hospital admissions in England: which may be avoidable and how? 2018.

4. NHS Digital. Ambulatory Care Sensitive Conditions (ACSC), https://digital.nhs.uk/dataand-information/data-tools-and-services/data-services/innovative-uses-ofdata/demand-on-healthcare/ambulatory-care-sensitive-conditions (2021, accessed 27 January 2021).

5. O'Cathain A, Knowles E, Turner J, et al. Explaining variation in emergency admissions: a mixed-methods study of emergency and urgent care systems. Heal Serv Deliv Res 2014; 2: 1-126.

6. McCormick B, Hill PS, Redding S. Comparative morbidities and the share of emergencies in hospital admissions in deprived areas: A method and evidence from English administrative data. BMJ Open 2018; 8: e022573.

7. Parkinson $B$, Meacock $R$, Checkland K, et al. How sensitive are avoidable emergency department attendances to primary care quality? Retrospective observational study. BMJ Qual Saf 2020; 0: 1-9.

8. Fisher R, Dunn P, Gershlick B, et al. Level or not? Epub ahead of print 26 September 2020. DOI: 10.37829/HF-2020-RC13.

9. Prentice JC, Pizer SD. Waiting times and hospitalizations for ambulatory care sensitive conditions. Heal Serv Outcomes Res Methodol 2008; 8: 1-18.

10. Office for National Statistics. Indices of Deprivation 2015 and 2019. 2019, http://dclgapps.communities.gov.uk/imd/iod_index.html\# (accessed 11 October 2019).

11. Department of Health. The Government's revised mandate to NHS England for 201718, https://assets.publishing.service.gov.uk/government/uploads/system/uploads/attach ment_data/file/692140/NHSE_Mandate_2017-18_revised.pdf (2018, accessed 11 October 2019).

12. NHS England. CCG Improvement and Assessment Framework 2018/19: Technical Annex. 2018.

13. Cookson R, Asaria M, Ali S, et al. Health Equity Indicators for the English NHS: a longitudinal whole-population study at the small-area level. Heal Serv Deliv Res 2016; 4: 1-224.

14. Equality and Health Inequality NHS RightCare Packs, https://www.england.nhs.uk/rightcare/products/ccg-data-packs/equality-and-healthinequality-nhs-rightcare-packs/ (2018, accessed 31 October 2019).

15. Pawson R. Evidence-based policy : a realist perspective. SAGE, 2006.

16. Health Research Authority. What do I need to do?, https://www.hra.nhs.uk/planningand-improving-research/best-practice/public-involvement/what-do-i-need-do/ (2020, accessed 9 June 2020).

17. Castro A, Cookson R, Doran T, et al. Local Equity Data Packs for England 2009-2018. 
Centre for Health Economics, University of York, https://www.york.ac.uk/che/research/equity/monitoring/packs/ (2019, accessed 21 July 2020).

18. Public Health England. Public Health Profiles. Public Health Profiles, https://fingertips.phe.org.uk/search/atrial\#page/7/gid/1/pat/15/par/E92000001/ati/ 152/are/E38000056/iid/92594/age/1/sex/4 (2019, accessed 12 June 2019).

19. Ranmuthugala G, Cunningham FC, Plumb JJ, et al. A realist evaluation of the role of communities of practice in changing healthcare practice. Implement Sci 2011; 6: 1-6.

20. Sowden S, Nezafat-Maldonado B, Wildman J, et al. Interventions to reduce inequalities in avoidable hospital admissions: Explanatory framework and systematic review protocol. BMJ Open 2020; 10: 35429.

21. Busby J, Purdy S, Hollingworth W. A systematic review of the magnitude and cause of geographic variation in unplanned hospital admission rates and length of stay for ambulatory care sensitive conditions. BMC Health Services Research; 15. Epub ahead of print 13 August 2015. DOI: 10.1186/s12913-015-0964-3.

22. Rosano A, Loha CA, Falvo $R$, et al. The relationship between avoidable hospitalization and accessibility to primary care: a systematic review. Eur J Public Health 2013; 23: 356-60.

23. Gibson OR, Segal L, McDermott RA. A systematic review of evidence on the association between hospitalisation for chronic disease related ambulatory care sensitive conditions and primary health care resourcing. BMC Health Serv Res 2013; 13: 336.

24. van Loenen T, van den Berg MJ, Westert GP, et al. Organizational aspects of primary care related to avoidable hospitalization: a systematic review. Fam Pract 2014; 31: 502-16.

25. Dusheiko $M$, Gravelle $H$, Martin S, et al. Does better disease management in primary care reduce hospital costs? Evidence from English primary care. J Health Econ 2011; 30: 919-32.

26. Sheringham J, Asaria $\mathrm{M}$, Barratt $\mathrm{H}$, et al. Are some areas more equal than others? Socioeconomic inequality in potentially avoidable emergency hospital admissions within english local authority areas. J Heal Serv Res Policy 2017; 22: 83-90.

27. Graverholt B, Forsetlund L, Jamtvedt G. Reducing hospital admissions from nursing homes: A systematic review. BMC Health Serv Res 2014; 14: 36.

28. Purdy S, Huntley A. Predicting and preventing avoidable hospital admissions: A review. J R Coll Physicians Edinb 2013; 43: 340-344.

29. Huntley AL, Chalder M, Shaw ARG, et al. A systematic review to identify and assess the effectiveness of alternatives for people over the age of 65 who are at risk of potentially avoidable hospital admission. BMJ Open; 7. Epub ahead of print 1 July 2017. DOI: 10.1136/bmjopen-2017-016236.

30. Focused Care. Focused Care Introductory Pack, http://focusedcare.org.uk/wpcontent/uploads/2017/01/Focused-Care-Intro-Pack-LR-Final2-1.pdf (2019, accessed 11 October 2019).

31. Barr B, Bambra C, Whitehead M, et al. The impact of NHS resource allocation policy on health inequalities in England 2001-11: Longitudinal ecological study. BMJ; 348. Epub ahead of print 27 May 2014. DOI: 10.1136/bmj.g3231. 
Figure 1: Overall programme theory diagram showing factors that influence inequality in avoidable emergency admissions

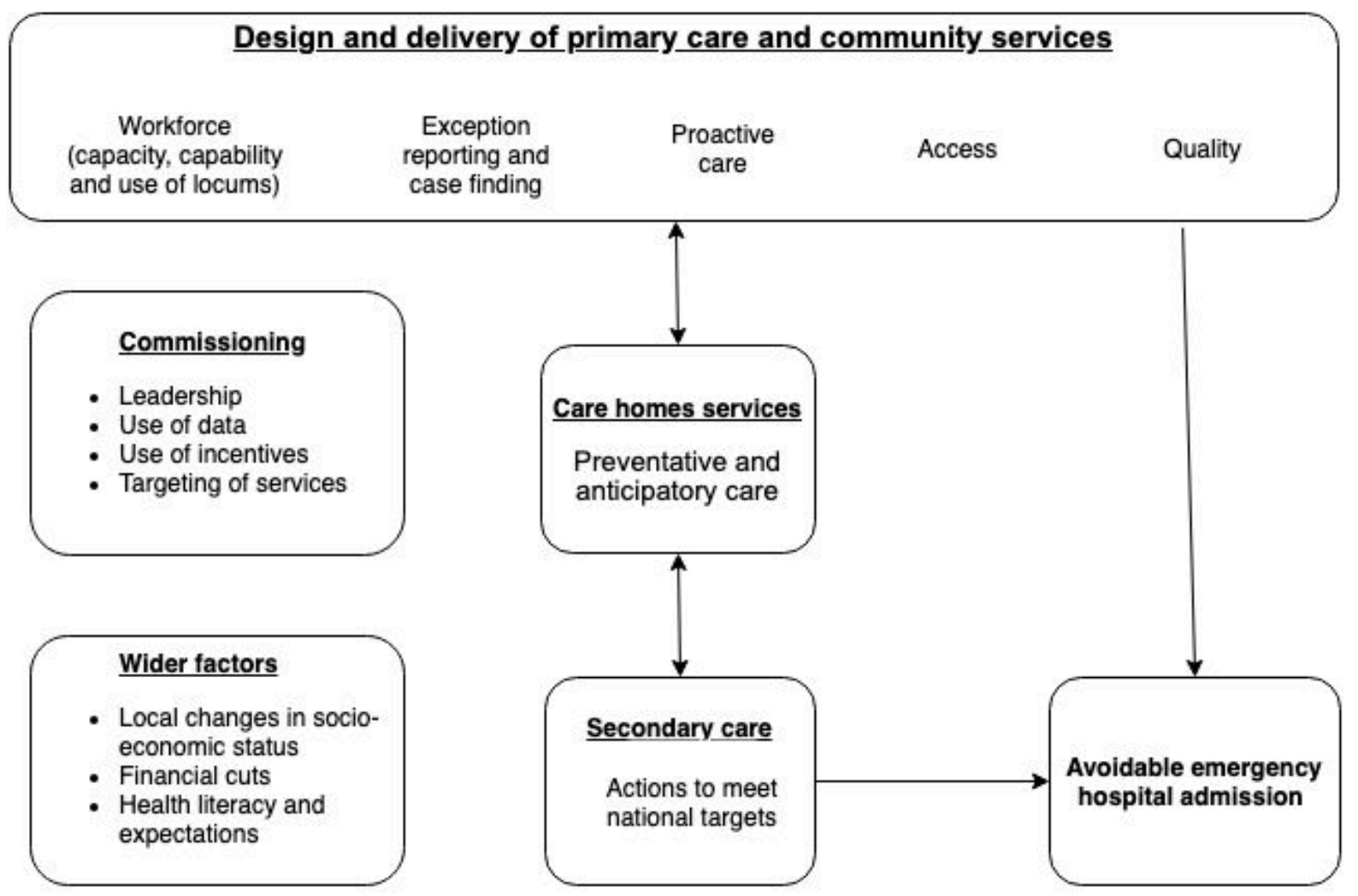


Table 1: Number of discussions conducted at each case study site

\begin{tabular}{|c|c|c|c|}
\hline $\begin{array}{l}\text { Chosen case study } \\
\text { site }\end{array}$ & $\begin{array}{l}\text { Commissioner } \\
\text { representatives } \\
\text { discussions }\end{array}$ & $\begin{array}{c}\text { Provider } \\
\text { representative } \\
\text { discussions }\end{array}$ & $\begin{array}{c}\text { Total number of } \\
\text { individuals spoken } \\
\text { to }\end{array}$ \\
\hline Pilot CCG & $\begin{array}{l}6 \text { representatives } \\
\text { (over } 6 \text { meetings) }\end{array}$ & $\begin{array}{l}3 \text { representatives } \\
\text { (over } 3 \text { meetings) }\end{array}$ & 9 \\
\hline CCG A-Improving & $\begin{array}{l}5 \text { representatives } \\
\text { (over } 5 \text { meetings) }\end{array}$ & $\begin{array}{l}\mathrm{Nil} \text { - no response } \\
\text { from providers }\end{array}$ & 5 \\
\hline CCG B-Improving & $\begin{array}{l}6 \text { representatives } \\
\text { (over } 3 \text { meetings) }\end{array}$ & $\begin{array}{l}2 \text { representatives } \\
\text { (over } 2 \text { meetings) }\end{array}$ & 8 \\
\hline CCG C-Mixed & $\begin{array}{l}5 \text { representatives } \\
\text { (over } 5 \text { meetings) }\end{array}$ & $\begin{array}{l}\text { Nil- cancelled by } \\
\text { provider }\end{array}$ & 5 \\
\hline CCG D-Worsening & $\begin{array}{l}6 \text { representatives } \\
\text { (over } 5 \text { meetings) }\end{array}$ & $\begin{array}{l}2 \text { representatives } \\
\text { (over } 2 \text { meetings) }\end{array}$ & 8 \\
\hline CCG E-Worsening & $\begin{array}{l}8 \text { representatives } \\
\text { (over } 7 \text { meetings) }\end{array}$ & $\begin{array}{l}2 \text { representatives } \\
\text { (over } 2 \text { meetings) }\end{array}$ & 10 \\
\hline
\end{tabular}


Table 2: Context-mechanism-outcome configurations relating to direct factors that influence inequality in emergency admissions listed by theme

\begin{tabular}{|c|c|c|c|c|}
\hline & Context & Mechanism & Outcome & $\begin{array}{l}\text { Case study } \\
\text { site(s) that can } \\
\text { provide } \\
\text { example of this }\end{array}$ \\
\hline \multicolumn{5}{|c|}{ Design and delivery of primary care and community services } \\
\hline 1 & $\begin{array}{l}\text { Worsening } \\
\text { primary care accessibility } \\
\text { and quality }\end{array}$ & $\begin{array}{l}\text { Unmet need and } \\
\text { inability to manage } \\
\text { complex cases in the } \\
\text { community } \\
\text { disproportionally } \\
\text { affecting } \\
\text { disadvantaged } \\
\text { patients }\end{array}$ & $\begin{array}{l}\text { Worsening } \\
\text { inequality in } \\
\text { A\&E } \\
\text { attendances } \\
\text { and admissions }\end{array}$ & $\begin{array}{c}\text { CCG E- } \\
\text { Worsening } \\
\text { CCG C-Mixed }\end{array}$ \\
\hline 2 & $\begin{array}{l}\text { Low exception } \\
\text { reporting and case finding } \\
\text { of hard to engage } \\
\text { patients }\end{array}$ & $\begin{array}{l}\text { Improved } \\
\text { engagement with } \\
\text { primary care }\end{array}$ & $\begin{array}{c}\text { Improving } \\
\text { quality of care } \\
\text { and increased } \\
\text { likelihood of } \\
\text { accessing } \\
\text { primary care } \\
\text { earlier and } \\
\text { during acute } \\
\text { deterioration }\end{array}$ & CCG C-Mixed \\
\hline 3 & $\begin{array}{c}\text { Focused pro-active care in } \\
\text { practices in } \\
\text { disadvantaged areas }\end{array}$ & $\begin{array}{l}\text { Improved } \\
\text { prevention, health } \\
\text { literacy, self- } \\
\text { management and } \\
\text { community } \\
\text { development }\end{array}$ & $\begin{array}{l}\text { Health } \\
\text { problems more } \\
\text { likely to be } \\
\text { addressed } \\
\text { earlier and in } \\
\text { the community }\end{array}$ & CCG C-Mixed \\
\hline 4 & $\begin{array}{c}\text { Dedicated workforce } \\
\text { targeted at disadvantaged } \\
\text { communities }\end{array}$ & $\begin{array}{l}\text { Support with health } \\
\text { and wider social } \\
\text { issues }\end{array}$ & $\begin{array}{l}\text { Increasing } \\
\text { likelihood of } \\
\text { managing } \\
\text { acute } \\
\text { conditions in } \\
\text { the community }\end{array}$ & CCG C-Mixed \\
\hline 5 & $\begin{array}{l}\text { Reducing primary and } \\
\text { community workforce in } \\
\text { disadvantaged areas }\end{array}$ & $\begin{array}{c}\text { Reduced capability } \\
\text { and capacity to deal } \\
\text { with acute } \\
\text { deteriorations in } \\
\text { disadvantaged areas }\end{array}$ & $\begin{array}{l}\text { Increasing } \\
\text { inequality in } \\
\text { admissions }\end{array}$ & $\begin{array}{l}\text { CCG E- } \\
\text { Worsening } \\
\text { Pilot CCG }\end{array}$ \\
\hline 6 & $\begin{array}{l}\text { High proportion of GPs } \\
\text { retiring in deprived areas } \\
\text { who are either not } \\
\text { replaced or replaced by }\end{array}$ & $\begin{array}{l}\text { Loss of experience, } \\
\text { senior leadership in } \\
\text { region and new staff } \\
\text { less willing to } \\
\text { tolerate risk }\end{array}$ & $\begin{array}{l}\text { Increased } \\
\text { likelihood of } \\
\text { onward } \\
\text { referral to }\end{array}$ & $\begin{array}{c}\text { CCG D- } \\
\text { Worsening }\end{array}$ \\
\hline
\end{tabular}




\begin{tabular}{|c|c|c|c|c|}
\hline & $\begin{array}{l}\text { younger doctors or allied } \\
\text { health professionals }\end{array}$ & & $\begin{array}{l}\text { hospital of } \\
\text { acute patients }\end{array}$ & \\
\hline 7 & $\begin{array}{l}\text { Increasing use of short- } \\
\text { term locums in } \\
\text { disadvantaged areas }\end{array}$ & $\begin{array}{l}\text { Reduced knowledge } \\
\text { of patients and } \\
\text { continuity of care }\end{array}$ & $\begin{array}{l}\text { Reducing } \\
\text { likelihood of } \\
\text { managing } \\
\text { patients in the } \\
\text { community }\end{array}$ & $\begin{array}{c}\text { CCG D- } \\
\text { Worsening } \\
\text { CCG E- } \\
\text { Worsening }\end{array}$ \\
\hline 8 & $\begin{array}{l}\text { Cultural and language } \\
\text { barriers coupled with } \\
\text { reduce consultation } \\
\text { capacity }\end{array}$ & $\begin{array}{l}\text { Increased } \\
\text { uncertainty of } \\
\text { diagnosis }\end{array}$ & $\begin{array}{c}\text { Increasing } \\
\text { likelihood of } \\
\text { short } \\
\text { admissions for } \\
\text { investigations } \\
\text { to rule out } \\
\text { disease }\end{array}$ & $\begin{array}{c}\text { CCG E- } \\
\text { Worsening }\end{array}$ \\
\hline 9 & $\begin{array}{l}\text { Merger of primary care } \\
\text { practices in under-served } \\
\text { areas and GP contracts } \\
\text { that support under- } \\
\text { doctored areas }\end{array}$ & $\begin{array}{c}\text { Increased } \\
\text { investment and } \\
\text { sustainability of } \\
\text { primary care in } \\
\text { deprived area }\end{array}$ & $\begin{array}{l}\text { Improving } \\
\text { access to } \\
\text { primary care in } \\
\text { deprived areas }\end{array}$ & $\begin{array}{c}\text { CCG B- } \\
\text { Improving } \\
\text { CCG C-Mixed }\end{array}$ \\
\hline \multicolumn{5}{|c|}{ Key performance indicators in secondary care settings } \\
\hline 10 & $\begin{array}{l}\text { Challenging high profile } \\
\text { A\&E targets }\end{array}$ & $\begin{array}{l}\text { Fear of missing } \\
\text { targets }\end{array}$ & $\begin{array}{l}\text { Increasing } \\
\text { likelihood of } \\
\text { admitting } \\
\text { patients with } \\
\text { complex health } \\
\text { or social needs }\end{array}$ & $\begin{array}{c}\text { CCG E- } \\
\text { Worsening } \\
\text { CCG C-Mixed }\end{array}$ \\
\hline \multicolumn{5}{|c|}{ Care homes } \\
\hline 11 & $\begin{array}{l}\text { Increasing services in care } \\
\text { homes which are } \\
\text { predominantly in } \\
\text { disadvantaged areas }\end{array}$ & $\begin{array}{l}\text { Preventative and } \\
\text { anticipatory care }\end{array}$ & $\begin{array}{l}\text { Reducing } \\
\text { admissions } \\
\text { from care } \\
\text { homes }\end{array}$ & $\begin{array}{l}\text { CCG C-Mixed } \\
\text { CCG A- } \\
\text { Improving }\end{array}$ \\
\hline \multicolumn{5}{|c|}{ Oversight and process of commissioning local health services } \\
\hline 12 & $\begin{array}{l}\text { Provision of bespoke } \\
\text { health data to GP for } \\
\text { comparison }\end{array}$ & Peer pressure & $\begin{array}{c}\text { Improving } \\
\text { performance of } \\
\text { worst } \\
\text { performing } \\
\text { practices and } \\
\text { reduced } \\
\text { likelihood of } \\
\text { secondary care } \\
\text { use }\end{array}$ & $\begin{array}{c}\text { CCG B- } \\
\text { Improving }\end{array}$ \\
\hline 13 & $\begin{array}{l}\text { Re-prioritisation of } \\
\text { financial incentives to } \\
\text { support struggling } \\
\text { primary and community } \\
\text { care }\end{array}$ & $\begin{array}{l}\text { Dis-incentivisation } \\
\text { of secondary care } \\
\text { and improved } \\
\text { engagement with } \\
\text { primary and } \\
\text { community care }\end{array}$ & $\begin{array}{l}\text { Reducing } \\
\text { secondary care } \\
\text { attendances } \\
\text { and admissions }\end{array}$ & $\begin{array}{c}\text { CCG B- } \\
\text { Improving }\end{array}$ \\
\hline
\end{tabular}




\begin{tabular}{|c|c|c|c|c|}
\hline 14 & $\begin{array}{l}\text { Access to and desire to } \\
\text { use data within } \\
\text { commissioning } \\
\text { organisation }\end{array}$ & $\begin{array}{l}\text { Improved } \\
\text { understanding of } \\
\text { local population }\end{array}$ & $\begin{array}{c}\text { Increasing } \\
\text { ability to target } \\
\text { services to } \\
\text { areas of } \\
\text { highest need } \\
\text { and inequality }\end{array}$ & $\begin{array}{l}\text { CCG B- } \\
\text { Improving } \\
\text { CCG A- } \\
\text { Improving }\end{array}$ \\
\hline \multicolumn{5}{|c|}{ Socio-economic, cultural and environmental changes in the local area } \\
\hline 15 & $\begin{array}{l}\text { Local area becoming } \\
\text { more affluent or } \\
\text { disadvantaged }\end{array}$ & $\begin{array}{l}\text { Changing health } \\
\text { care need of local } \\
\text { population }\end{array}$ & $\begin{array}{c}\text { Changing } \\
\text { secondary care } \\
\text { use }\end{array}$ & $\begin{array}{c}\text { CCG A- } \\
\text { Improving } \\
\text { CCG C-Mixed } \\
\text { CCG E- } \\
\text { Worsening }\end{array}$ \\
\hline 16 & $\begin{array}{l}\text { Financial constraints of } \\
\text { public services coupled } \\
\text { with universal credit }\end{array}$ & $\begin{array}{l}\text { Worsening } \\
\text { community } \\
\text { resilience and } \\
\text { income deprivation }\end{array}$ & $\begin{array}{l}\text { Reducing } \\
\text { health and } \\
\text { ability to } \\
\text { manage } \\
\text { increased need } \\
\text { in the } \\
\text { community }\end{array}$ & CCG C-Mixed \\
\hline 17 & $\begin{array}{c}\text { Different experience and } \\
\text { expectations of the health } \\
\text { care system }\end{array}$ & $\begin{array}{l}\text { Confusion and } \\
\text { reduced health } \\
\text { literacy }\end{array}$ & $\begin{array}{c}\text { Increasing } \\
\text { likelihood of } \\
\text { attendance at } \\
\text { A\&E and } \\
\text { subsequent } \\
\text { admission } \\
\end{array}$ & $\begin{array}{l}\text { CCG E- } \\
\text { Worsening } \\
\text { Pilot CCG }\end{array}$ \\
\hline
\end{tabular}

